\title{
Enhancement in thermoelectric properties due to Ag nanoparticles incorporated in $\mathrm{Bi}_{2} \mathrm{Te}_{3}$ matrix
}

\author{
Srashti Gupta ${ }^{* 1}$, Dinesh Chandra Agarwal ${ }^{*}$, Bathula Sivaiah ${ }^{3}$, \\ Sankarakumar Amrithpandian ${ }^{4}$, Kandasami Asokan ${ }^{5}$, Ajay Dhar ${ }^{3}$, \\ Binaya Kumar Panigrahi ${ }^{4}$, Devesh Kumar Avasthi ${ }^{6}$ and Vinay Gupta ${ }^{1}$
}

\author{
Full Research Paper \\ Address: \\ ${ }^{1}$ Department of Physics and Astrophysics, University of Delhi, New \\ Delhi-110007, India, ${ }^{2}$ Department of Physics, Sant Longowal Institute \\ of Engg and Tech. Longowal, Punjab-148106, India, ${ }^{3}$ Physics of \\ Energy Harvesting Division, CSIR - National Physical Laboratory, \\ Delhi-110007, India, ${ }^{4}$ Materials Physics Division, Indira Gandhi \\ Centre for Atomic Research, Kalpakkam-603102, India, ${ }^{5}$ Material \\ Science, Inter University Accelerator Centre, New Delhi, Delhi \\ 110067, India and ${ }^{6}$ Amity Institute of Nanotechnology, Amity \\ University, Noida-Uttar Pradesh-201303, India \\ Email: \\ Srashti Gupta* - Srashti.3@gmail.com; Dinesh Chandra Agarwal ${ }^{*}$ - \\ dcagarwal@gmail.com \\ * Corresponding author \\ Keywords: \\ bismuth telluride; nanoparticles; power factor; thermoelectric power
}

\author{
Beilstein J. Nanotechnol. 2019, 10, 634-643. \\ doi:10.3762/bjnano. 10.63 \\ Received: 15 August 2018 \\ Accepted: 06 February 2019 \\ Published: 04 March 2019 \\ Associate Editor: N. Motta \\ (C) 2019 Gupta et al.; licensee Beilstein-Institut. \\ License and terms: see end of document.
}

\begin{abstract}
The present study aims to see the enhancement in thermoelectric properties of bismuth telluride $\left(\mathrm{Bi}_{2} \mathrm{Te}_{3}\right)$ annealed at different temperatures $(573$ and $773 \mathrm{~K})$ through silver $(\mathrm{Ag})$ nano-inclusions $(0,2,5,10,15$ and $20 \mathrm{wt} \%)$. Transmission electron microscopy (TEM) images of $\mathrm{Ag}$ incorporated in $\mathrm{Bi}_{2} \mathrm{Te}_{3}$ annealed at $573 \mathrm{~K}$ shows tubular, pentagonal, trigonal, circular and hexagonal nanoparticles with sizes of 6-25 nm (for $5 \mathrm{wt} \% \mathrm{Ag}$ ) and 7-30 nm (for $20 \mathrm{wt} \% \mathrm{Ag}$ ). Ag incorporated in $\mathrm{Bi}_{2} \mathrm{Te}_{3}$ annealed at $773 \mathrm{~K}$ shows mainly hexagonally shaped structures with particle sizes of 2-20 nm and 40-80 nm (for $5 \mathrm{wt} \% \mathrm{Ag}$ ) and 10-60 nm (for $20 \mathrm{wt} \% \mathrm{Ag}$ ). Interestingly, the samples annealed at $573 \mathrm{~K}$ show the highest Seebeck coefficient ( $S$, also called thermopower) at room temperature (p-type behavior) for $5 \% \mathrm{Ag}$ which is increased ca. five-fold in comparison to $\mathrm{Ag}$-free $\mathrm{Bi}_{2} \mathrm{Te}_{3}$, whereas for samples with the same content $(5 \% \mathrm{Ag})$ annealed at $773 \mathrm{~K}$ the increment in thermopower is only about three-fold with a 6.9 -fold enhancement of the power factor $\left(S^{2} \sigma\right)$. The effect of size and shape of the nanoparticles on thermoelectric properties can be understood on the basis of a carrier-filtering effect that results in an increase in thermopower along with a control over the reduction in electrical conductivity to maintain a high power factor yielding a high figure of merit.
\end{abstract}




\section{Introduction}

Bismuth telluride $\left(\mathrm{Bi}_{2} \mathrm{Te}_{3}\right)$ is an important semiconductor widely used as thermoelectric (TE) material for room-temperature applications to convert waste heat into electricity. The efficiency of a TE material can be defined by figure of merit $\left(\mathrm{ZT}=S^{2} \sigma T / k\right)$ and to enhance figure of merit $(\mathrm{ZT})$, one needs to increase the power factor $\left(S^{2} \sigma\right.$, where $S$ is the Seebeck coefficient or thermopower, $\sigma$ is the electrical conductivity) or to decrease thermal conductivity $(k)$. In bulk, all three parameters $(S$ $\sigma, k)$ are interdependent. In bulk $\mathrm{Bi}_{2} \mathrm{Te}_{3}, \mathrm{ZT}$ is close to unity, it can be improved further with the introduction of nanostructures. The electron and phonon energy spectra can be controlled by tuning the size of nanostructures, which opens up new ways for ZT enhancement [1,2]. Since the introduction of nanotechnology in TE in 1993, various methods have been tried and it remained a challenge to fabricate highly efficient low-cost TE devices of nanostructured $\mathrm{Bi}_{2} \mathrm{Te}_{3}$ for industrial and daily life applications [1-7]. $\mathrm{Bi}_{2} \mathrm{Te}_{3}$ and its derivatives with $\mathrm{Sb}$ (p-type) and $\mathrm{Se}$ (n-type) are the best known commercial materials for room-temperature applications but these materials are not very efficient because of their low ZT $[8,9]$.

To increase ZT, nanostructures play an important role in the simultaneous increase in power factor and reduction in phonon thermal conductivity $\left(k_{\mathrm{ph}}\right)$ [10]. Recently, Faleev et al. [11] and Zebardaji et al. [12] performed theoretical calculations for the introduction of metal nano-inclusions in TE materials. This theory predicts the band bending at the metal-semiconductor interface will allow for the transmission of high energy electrons along with a blocking of low energy electrons. This electron energy filter results in enhancement of the Seebeck coefficient for a given carrier concentration. Several groups have used this approach using different metal-semiconductor combinations to improve thermoelectric properties $[13,14]$. One group has reported the synthesis of bismuth metal nanoparticles (NPs) were through a solvothermal method and the incorporation in $\mathrm{Bi}_{2} \mathrm{Te}_{3}$ synthesized by ball milling, which yielded a significant enhancement in power factor and $\mathrm{ZT}$ in $\mathrm{Bi} / \mathrm{Bi}_{2} \mathrm{Te}_{3}$ due to the scattering of low-energy electrons by a barrier potential at the $\mathrm{Bi}-\mathrm{Bi}_{2} \mathrm{Te}_{3}$ interface [15].

Improvement in TE properties has also been observed after the uniform dispersion of carbon nanotubes (CNTs) in $\mathrm{Bi}_{2} \mathrm{Te}_{3}$ [16] Another group has also reported an enhancement of the Seebeck coefficient $(S)$ in $\mathrm{CNT} / \mathrm{Bi}_{2} \mathrm{Te}_{3}$ to $132 \mu \mathrm{V} / \mathrm{K}$ at $423 \mathrm{~K}$ [17]. In a recent report, a power factor of $43 \mu \mathrm{W} \cdot \mathrm{cm}^{-1} \cdot \mathrm{K}^{-2}$ for CuI-doped $\mathrm{Bi}_{2} \mathrm{Te}_{3}$ has been shown, which is higher than that of undoped $\mathrm{Bi}_{2} \mathrm{Te}_{3}$ and $\mathrm{Cu}$-doped $\mathrm{Bi}_{2} \mathrm{Te}_{3}$ [18]. There are reports on $\mathrm{Ag}$ incorporation in $\mathrm{Bi}_{2} \mathrm{Te}_{3}$ especially for the preparation of $1 \mathrm{D} / 3 \mathrm{D}$ structured $\mathrm{AgNWs} / \mathrm{Bi}_{2} \mathrm{Te}_{3}$ nanocomposites with enhanced thermoelectric properties, about $343 \%$ higher than that of pure
$\mathrm{Bi}_{2} \mathrm{Te}_{3}$ [19]. Recently, Ag nanoparticles in a $\mathrm{Bi}_{2} \mathrm{Te}_{3}$ matrix have been synthesized and a dramatic enhancement in ZT by $304 \%$ for 2 vol \% Ag in $\mathrm{Bi}_{2} \mathrm{Te}_{3}$ has been reported [20]. One research group submitted a patent on solvothermally synthesized low-dimensional nanocrystals of bismuth telluride covered by $0.001 \mathrm{wt} \%, 0.05 \mathrm{wt} \% \mathrm{Au}$ or $0.05 \mathrm{wt} \% \mathrm{Ag}$ metallic nanoparticles that yield both a higher power factor and figure of merit than pure $\mathrm{Bi}_{2} \mathrm{Te}_{3}$ [21].

An enhanced Seebeck coefficient $(S)$ could compensate for the reduction in electrical conductivity to some extent maintaining $S^{2} \sigma$ as unaffected as possible. Through the metal fraction in the matrix or the synthesis conditions, one can control $S, \sigma$, or $k$ independently. The above approaches showed issues regarding high cost and complicated syntheses that were difficult to repeat and unsuitable for scale-up. The enhancement in TE properties through $\mathrm{Ag}$ metal in a $\mathrm{Bi}_{2} \mathrm{Te}_{3}$ matrix motivated us to work on a detailed investigation of $\mathrm{Ag}$ in a $\mathrm{Bi}_{2} \mathrm{Te}_{3}$ matrix while focusing on an easy, reproducible low-cost synthesis suitable for scaleup. We show how to tune $S$ and $\sigma$ independently to achieve high $S^{2} \sigma$ values. One objective is to see which fraction of metal nanoparticles is required for the TE enhancement of a $\mathrm{Bi}_{2} \mathrm{Te}_{3}$ matrix and how different annealing temperatures lead to the different sizes and shapes of nanoparticles with different influence on thermoelectric properties. We have used different amounts of Ag microparticles (0, 2. 5, 10, 15 and $20 \mathrm{wt} \%)$ uniformly mixed with commercially purchased $\mathrm{Bi}_{2} \mathrm{Te}_{3}$, which was annealed at different temperatures (573 and $773 \mathrm{~K}$ ).

\section{Experimental}

Bismuth telluride $\left(\mathrm{Bi}_{2} \mathrm{Te}_{3}\right)$ powder was purchased from Alfa Aesar (99.99\% purity). Silver (Ag) powder (7-15 $\mu$ m particles) was purchased from Ted Pella Inc. Different fractions $(0,2,5$, 10,15 and $20 \mathrm{wt} \%$ ) of $\mathrm{Ag}$ powder were added to $\mathrm{Bi}_{2} \mathrm{Te}_{3}$. The powder mixtures were well grinded and pressed to pellets. These pellets were then annealed at 573 or $773 \mathrm{~K}$ for $1 \mathrm{~h}$ under Ar atmosphere. Annealing temperatures were chosen to be below the melting point of $\mathrm{Bi}_{2} \mathrm{Te}_{3}\left(586{ }^{\circ} \mathrm{C}\right)$ and above the melting points of $\mathrm{Bi}\left(271^{\circ} \mathrm{C}\right)$ and $\mathrm{Te}\left(449^{\circ} \mathrm{C}\right)$. These samples were characterized by X-ray diffraction (XRD), transmission electron microscopy (TEM), and thermoelectric measurements. XRD measurements were performed using a Bruker D8 Avance diffractometer with $\mathrm{Cu} \mathrm{K} \alpha(1.5406 \AA)$ radiation. TEM investigations were carried out using a LIBRA 200 FE HRTEM. Gatan software [22] was used for analysis of HRTEM images of samples. Scanning electron microscopy with energy-dispersive spectroscopy (SEM EDS) was performed using a field-emission scanning electron microscope (FE-SEM) [MIRA $\backslash$, TESCAN]. Temperature-dependent thermoelectric measurements were carried out for all samples with size using a com- 
mercial instrument (Ulvac, ZEM3). The instrument error during TE measurements is $\pm 5 \%$.

\section{Results and Discussion}

$\mathrm{X}$-ray diffraction and transmission electron microscopy selected area electron diffraction

$\mathrm{X}$-ray diffraction $(\mathrm{XRD})$ patterns of $\mathrm{Bi}_{2} \mathrm{Te}_{3}$ with different concentrations of $\mathrm{Ag}(0,5$ and $20 \mathrm{wt} \%)$ annealed at 573 and $773 \mathrm{~K}$ are shown in Figure 1a. The XRD patterns show main peaks of $\mathrm{Bi}_{2} \mathrm{Te}_{3}$ (rhombohedral) at $2 \theta=27.8^{\circ}(d$-spacing: $\approx 0.321 \mathrm{~nm})$, $37.98^{\circ}(\approx 0.237 \mathrm{~nm}), 40.2^{\circ}(\approx 0.223 \mathrm{~nm}), 41.2^{\circ}(\approx 0.219 \mathrm{~nm})$, $44.58^{\circ}(\approx 0.203 \mathrm{~nm}), 50.4^{\circ}(\approx 0.181 \mathrm{~nm}), 54.12^{\circ}(\approx 0.169 \mathrm{~nm})$ and $57.2^{\circ}(\approx 0.161 \mathrm{~nm})$ corresponding to the $\left(\begin{array}{lll}0 & 1 & 5\end{array}\right),\left(\begin{array}{lll}1 & 0 & 10\end{array}\right)$,

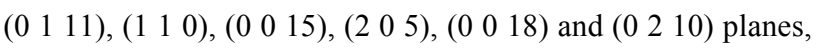
respectively (JCPDS 15-0863). There are some peaks marked with $(*)$, which are speculated to be $\mathrm{Bi}_{2} \mathrm{TeO}_{5}$ (orthorhombic) for $2 \theta=30.97^{\circ}(\approx 0.289 \mathrm{~nm})$ and $55.79^{\circ}(\approx 0.166 \mathrm{~nm})$ corresponding to the ( $\left(\begin{array}{lll}0 & 0 & 4\end{array}\right)$ and $\left(\begin{array}{lll}9 & 1 & 2\end{array}\right)$ planes, respectively (JCPDS 38-0420). At Ag concentrations of $5 \%$ and $20 \%$ in $\mathrm{Bi}_{2} \mathrm{Te}_{3}$ after
$773 \mathrm{~K}$ annealing, all peaks are at the same positions. In samples with 5 and $20 \% \mathrm{Ag}$, annealed at $573 \mathrm{~K}$, two peaks at $2 \theta=37.98^{\circ}$ and $44.58^{\circ}$ matching the $\left(\begin{array}{lll}1 & 1 & 1\end{array}\right)$ and $\left(\begin{array}{lll}2 & 0 & 0\end{array}\right)$ planes of cubic with Ag (JCPDS-04-0783), respectively, can be seen. $\mathrm{Bi}_{2} \mathrm{Te}_{3}$ and $\mathrm{Ag}$ planes are in good agreement with the literature [20]. Figure $1 \mathrm{~b}$ shows the XRD of commercially purchased $\mathrm{Bi}_{2} \mathrm{Te}_{3}$ and $\mathrm{Ag}$ powder without annealing.

The XRD results have also been verified by transmission electron microscopy selected area electron diffraction (TEM SAED) patterns of $\mathrm{Bi}_{2} \mathrm{Te}_{3}$ as shown in Figure $1 \mathrm{c}(0 \% \mathrm{Ag})$ and Figure $1 \mathrm{~d}(5 \% \mathrm{Ag})$ annealed at $573 \mathrm{~K}$. The planes in the SAED patterns were assigned using the Gatan software [22]. In Figure $1 \mathrm{c}, \mathrm{Bi}_{2} \mathrm{Te}_{3}$ with $0 \% \mathrm{Ag}$, the identified planes for $\mathrm{Bi}_{2} \mathrm{Te}_{3}$ were (0 $\left.10 \begin{array}{ll}0 & 1\end{array}\right),\left(\begin{array}{lll}0 & 0 & 15\end{array}\right),\left(\begin{array}{lll}0 & 0 & 18\end{array}\right),\left(\begin{array}{lll}2 & 1 & 10\end{array}\right),\left(\begin{array}{lll}1 & 0 & 25\end{array}\right)$ and $\left(\begin{array}{lll}0 & 2 & 25\end{array}\right)$. In Figure 1d the identified planes for $\mathrm{Bi}_{2} \mathrm{Te}_{3}$ were (from 1 to 5 ): $\left(\begin{array}{lll}0 & 0 & 15\end{array}\right),\left(\begin{array}{lll}2 & 0 & 5\end{array}\right),\left(\begin{array}{lll}1 & 1 & 18\end{array}\right),\left(\begin{array}{lll}1 & 0 & 25\end{array}\right)$ and $\left(\begin{array}{lll}0 & 2 & 25\end{array}\right)$ respectively, whereas few planes were also assigned to $\mathrm{Ag}$, i.e., ring 1 :

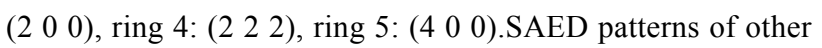
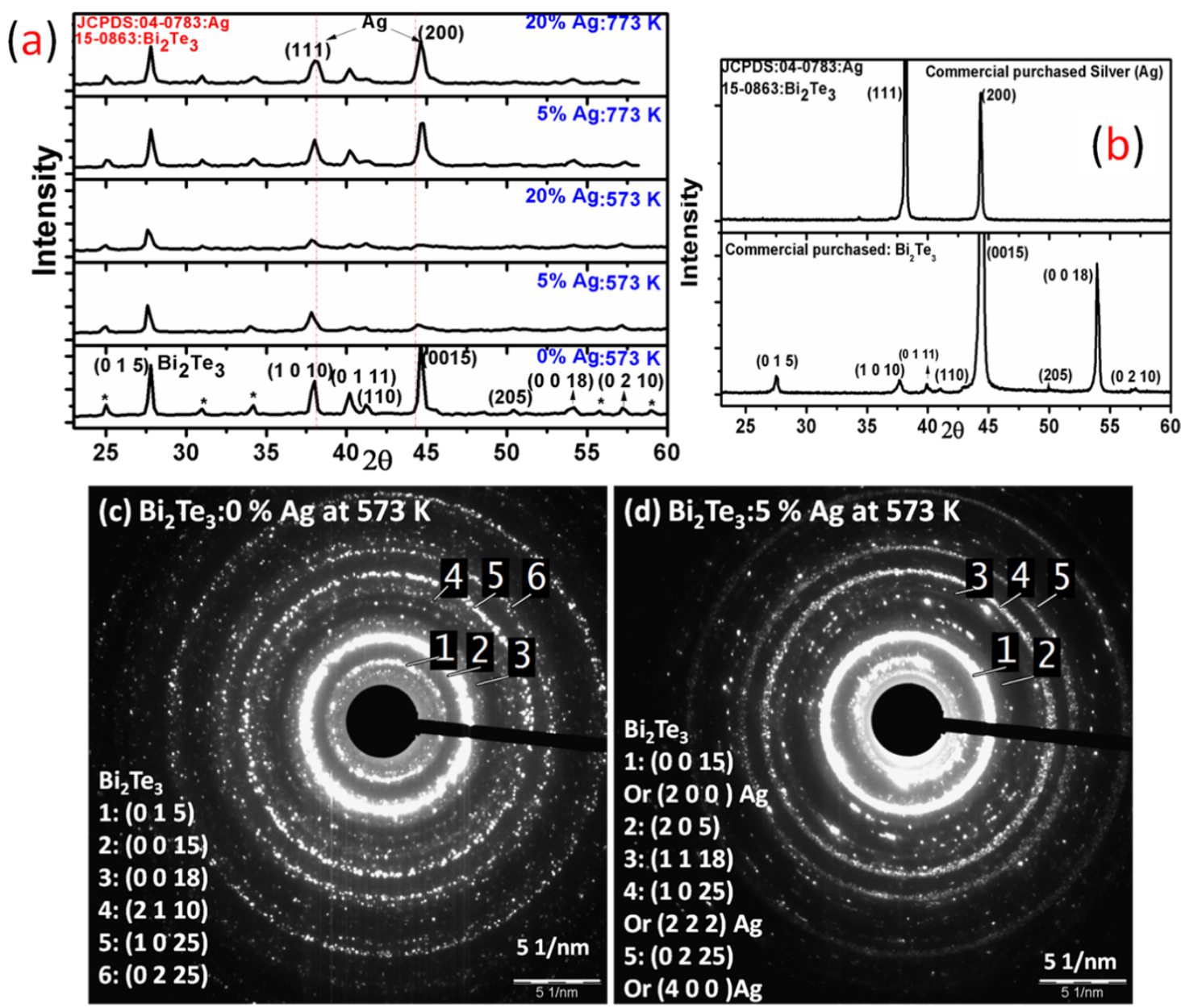

Figure 1: (a) XRD of $\mathrm{Bi}_{2} \mathrm{Te}_{3}$ with different concentration of $\mathrm{Ag}(0,5,20 \%)$ for annealing temperature $573 \mathrm{~K}, 773 \mathrm{~K}$, (b) XRD of commercial purchased $\mathrm{Ag}, \mathrm{Bi}_{2} \mathrm{Te}_{3}$ powder without annealing. SAED pattern of (c) $\mathrm{Bi}_{2} \mathrm{Te}_{3}$ and (d) $\mathrm{Ag}(5 \%)$ for annealing temperature $573 \mathrm{~K}$. 
samples, such as $20 \% \mathrm{Ag}$ annealed at $573 \mathrm{~K}$, and $5 \%$ and $20 \% \mathrm{Ag}$ annealed at $773 \mathrm{~K}$ show the same plane indexing with negligible differences.

\section{Scanning electron microscopy with energy dispersive spectroscopy (SEM EDS)}

SEM EDS measurements of $\mathrm{Bi}_{2} \mathrm{Te}_{3}: \mathrm{Ag}$ ( $5 \%$ and $20 \% \mathrm{Ag}$ ) annealed at $573 \mathrm{~K}$ are shown in Figure 2a and Figure 2b, respectively. The values are averages of measurements at different locations. Ag, Bi and Te are present throughout the samples. The presence of oxygen cannot be neglected in the samples as its composition varies from $3.4 \%$ to $4.78 \%$ with an increase in $\mathrm{Ag}$ from $5 \%$ to $20 \%$. From the SEM images and SEM EDS it is observed that $\mathrm{Ag}$ is well mixed with $\mathrm{Bi}_{2} \mathrm{Te}_{3}$.

\section{High-resolution transmission electron microscopy}

Transmission electron microscopy (TEM) and high-resolution TEM (HRTEM) images of $\mathrm{Bi}_{2} \mathrm{Te}_{3}$ :Ag samples annealed at $573 \mathrm{~K}$ are shown in Figure 3. Figure 3a,b shows the bright-field image and the HRTEM image of the as-prepared $\mathrm{Bi}_{2} \mathrm{Te}_{3}$ samples with no Ag content. There is a wide distribution of particles with various shapes and sizes. To estimate the particles size, the ImageJ software [23] has been used, which yielded an average particles size of the circular nanoparticles of 7-8 nm. The bigger hexagonal shaped particles are of ca. $100 \mathrm{~nm}$ and the small triangular and hexagonal nanoparticles are in the range of $40-70 \mathrm{~nm}$.

Figure $3 \mathrm{c}$, d shows the bright-field image and the HRTEM image of $\mathrm{Bi}_{2} \mathrm{Te}_{3}$ samples with $5 \% \mathrm{Ag}$ annealed at $573 \mathrm{~K}$. Figure $3 \mathrm{e}, \mathrm{f}$ shows the bright-field image and the HRTEM image of $\mathrm{Bi}_{2} \mathrm{Te}_{3}$ samples with $20 \% \mathrm{Ag}$ annealed at $573 \mathrm{~K}$ with nanoparticles of various shapes and sizes ranging from 7 to $30 \mathrm{~nm}$. In the HRTEM image (Figure 3f) we observed some particles with interesting shapes.

TEM measurements of $\mathrm{Bi}_{2} \mathrm{Te}_{3}$ with $5 \%$ and $20 \% \mathrm{Ag}$ annealed at $773 \mathrm{~K}$ have also been performed as shown in Figure $4 \mathrm{a}$ and Figure $4 \mathrm{~b}$, respectively. Figure $4 \mathrm{a}$ shows the bright-field image
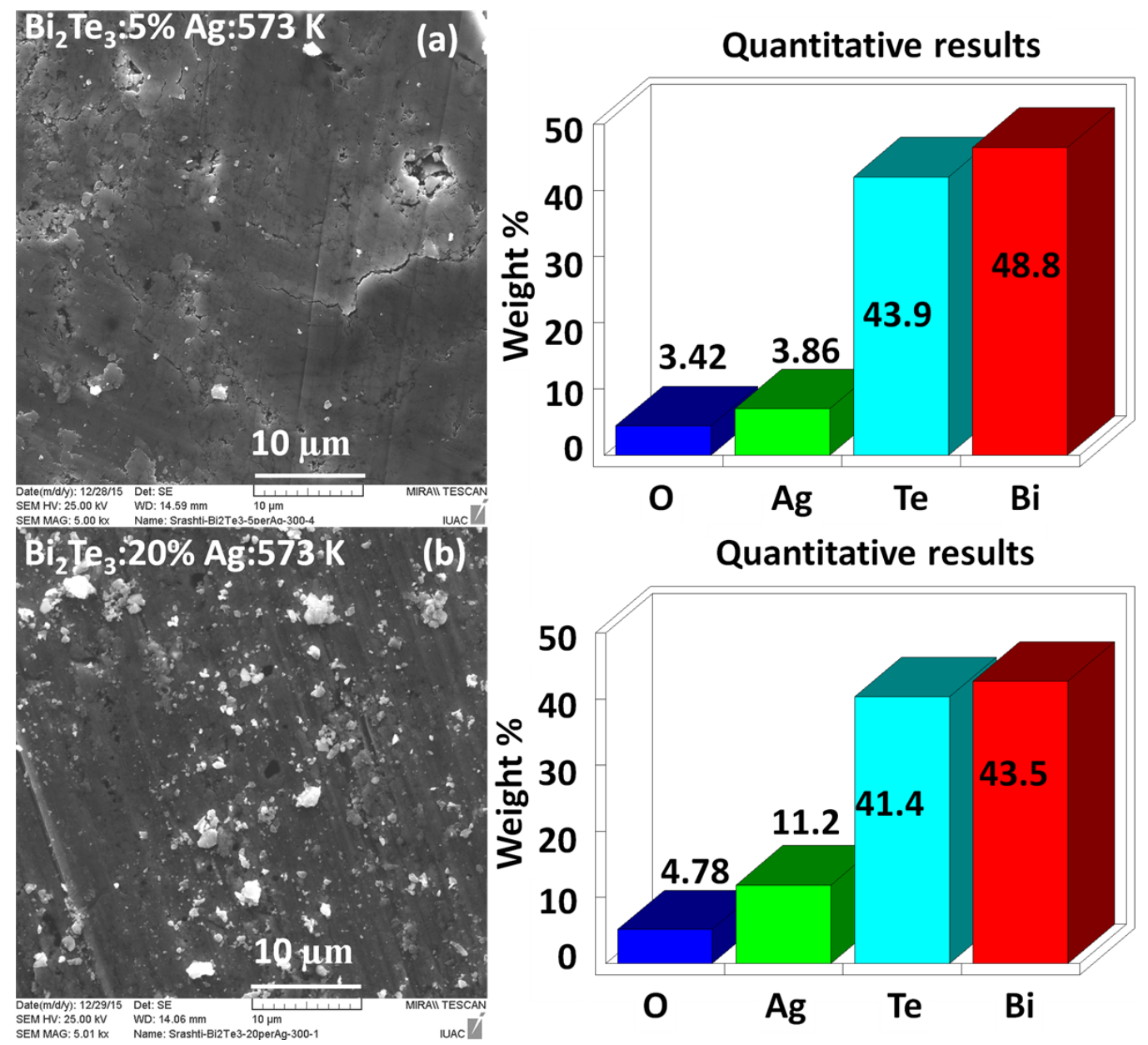

Figure 2: SEM and SEMEDS images of $\mathrm{Bi}_{2} \mathrm{Te}_{3}$ with (a) for $5 \% \mathrm{Ag}$, (b) for $20 \% \mathrm{Ag}$ annealed at $573 \mathrm{~K}$. 


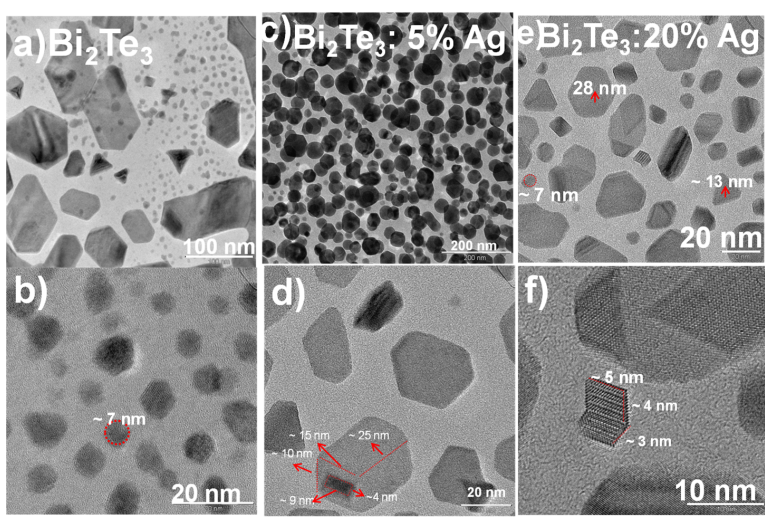

Figure 3: (a) TEM and (b) HRTEM images of $\mathrm{Bi}_{2} \mathrm{Te}_{3}$ with $0 \% \mathrm{Ag}$, (c, d) for $5 \% \mathrm{Ag},(\mathrm{e}, \mathrm{f}) 20 \% \mathrm{Ag}$ annealed at $573 \mathrm{~K}$.

and the HRTEM image of the $\mathrm{Bi}_{2} \mathrm{Te}_{3}$ sample $5 \% \mathrm{Ag}$ annealed at $773 \mathrm{~K}$. One can observe nanoparticles with 3D hexagonal structures along with smaller hexagonal structures which vary from 40 to $80 \mathrm{~nm}$ for the large structures and from 2 to $20 \mathrm{~nm}$ for the small structures. Figure $4 \mathrm{~b}$ of $\mathrm{Bi}_{2} \mathrm{Te}_{3}$ with $20 \mathrm{wt} \% \mathrm{Ag}$ annealed at $773 \mathrm{~K}$ shows that particles with mostly hexagonal shaped structures with a wide distribution of sizes from 10 to $60 \mathrm{~nm}$ are formed.

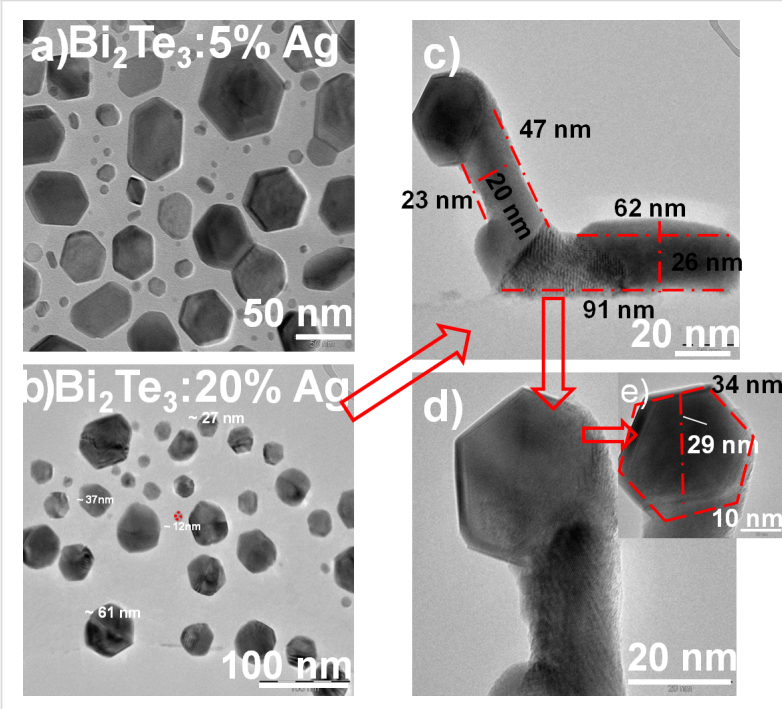

Figure 4: TEM of $\mathrm{Bi}_{2} \mathrm{Te}_{3}$ with (a) $5 \%$ and (b) $20 \% \mathrm{Ag}$ annealed at $773 \mathrm{~K},(\mathrm{c}, \mathrm{d}, \mathrm{e}) \mathrm{HRTEM}$ images of $\mathrm{Bi}_{2} \mathrm{Te}_{3}$ with $20 \% \mathrm{Ag}$ annealed at $773 \mathrm{~K}$.

In the samples annealed at $573 \mathrm{~K}$ there are different shapes, such as tubes, pentagons, triangles, disks and hexagons. Whereas in the samples annealed at $773 \mathrm{~K}$, one can see mainly hexagonal structures. Besides comparison in shapes of the structures size can also be compared in both cases $(5 \%, 20 \%)$. In the case of $5 \% \mathrm{Ag}$ annealed at $773 \mathrm{~K}$, there is a wide distribution in par- ticle sizes from 2 to $20 \mathrm{~nm}$ and from 40 to $80 \mathrm{~nm}$, while the particles siazes are $6-25 \mathrm{~nm}$ in the sample annealed at $573 \mathrm{~K}$. In the case of $20 \% \mathrm{Ag}$ a distribution from 10 to $60 \mathrm{~nm}$ for samples annealed at $773 \mathrm{~K}$ and a distribution from 7 to $30 \mathrm{~nm}$ for samples annealed at $573 \mathrm{~K}$ have been observed.

In Figure 4c and Figure 4d, a duck-like structure has been observed although it is not present everywhere. It appears to be a combination of hexagonal and tube shaped structures. Its dimensions have been measured, which fit well in the range of particle sizes shown in Figure $4 \mathrm{~b}$.

\section{Thermoelectric measurements \\ Electrical conductivity measurements}

Measurements of the electrical conductivity $(\sigma)$ in the range of $300-600 \mathrm{~K}$ of all samples are shown in Figure 5. The electrical conductivity of all samples increases with increasing temperature as it is expected for a non-degenerated semiconductor. The electrical conductivity of $\mathrm{Bi}_{2} \mathrm{Te}_{3}$ samples with $(5,20 \mathrm{wt} \%) \mathrm{Ag}$ increases after annealing to higher temperature $773 \mathrm{~K}$ in comparison to $573 \mathrm{~K}$ annealed samples as shown in Figure $5 \mathrm{~b}$.
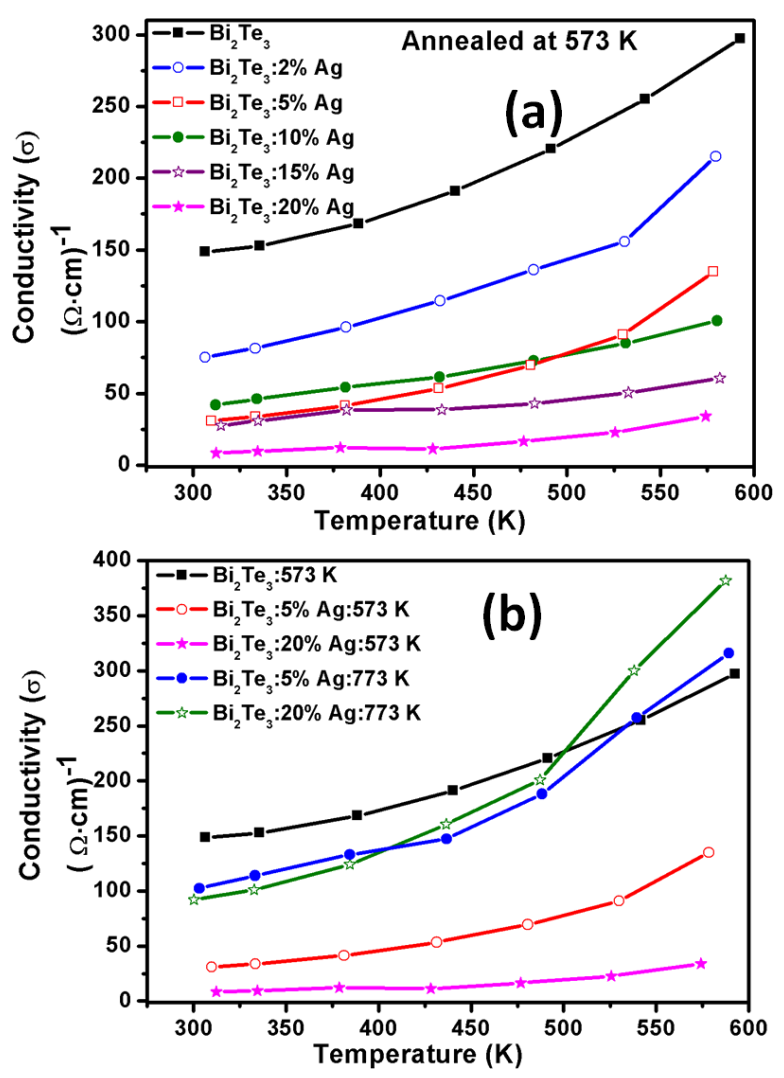

Figure 5: Electrical conductivity $(\sigma)$ of $(\mathrm{a}) \mathrm{Bi}_{2} \mathrm{Te}_{3}$ with $(0,2,5,10,15$ and $20 \%$ ) Ag annealed at $573 \mathrm{~K}$ as a function of the temperature; (b) comparison of samples $(0,5,20 \%) \mathrm{Ag}$ annealed at $573 \mathrm{~K}$ with $(5$, $20 \%) \mathrm{Ag}$ annealed at $773 \mathrm{~K}$. 
The electrical conductivity measured at room temperature shows that there is a systematic decrease with increasing $\mathrm{Ag}$ content. The highest electrical conductivity at $300 \mathrm{~K}$ is ca. $148(\Omega \cdot \mathrm{cm})^{-1}$ for $\mathrm{Ag}$-free $\mathrm{Bi}_{2} \mathrm{Te}_{3}$, which decreases by ca. $94 \%$ after addition of Ag up to $20 \%$ and annealing at $573 \mathrm{~K}$. A decrease by ca. $31 \%$ was observed for $5 \% \mathrm{Ag}$ annealed at $773 \mathrm{~K}$ The conductivity of Ag-free $\mathrm{Bi}_{2} \mathrm{Te}_{3}$ measured at $600 \mathrm{~K}$ is ca. $297(\Omega \cdot \mathrm{cm})^{-1}$, which decreases by ca. $88 \%$ for $20 \% \mathrm{Ag}$ annealed at $573 \mathrm{~K}$.

The decrease in electrical conductivity with increase in $\mathrm{Ag}$ content in $\mathrm{Bi}_{2} \mathrm{Te}_{3}$ may be due to the enhanced carrier scattering at the interfaces of metal and semiconductor [20] and due to the presence of oxygen in all samples. An earlier report also suggests that the electrical resistivity of $\mathrm{PbTe}$ can increase up to 2-3 orders of magnitude after exposure to air [24]. On the other hand conductivity is higher for samples annealed at $773 \mathrm{~K}$ in comparison to $573 \mathrm{~K}$, which may be due to the variation in particle-size distribution. As discussed above, the particle sizes are small in samples annealed at $573 \mathrm{~K}$ whereas they are larger in samples annealed at $773 \mathrm{~K}$.

\section{Measurement of the Seebeck coefficient $(S)$}

Figure 6a shows the Seebeck coefficient as a function of the temperature $(300-600 \mathrm{~K})$ of $\mathrm{Bi}_{2} \mathrm{Te}_{3}$ with $(0,2,5,10,15,20 \%)$ Ag content annealed at $573 \mathrm{~K}$. A comparison of $\mathrm{Bi}_{2} \mathrm{Te}_{3}$ samples $(0 \%, 5 \%, 20 \% \mathrm{Ag})$ annealed at $573 \mathrm{~K}$ with samples $(5$, $20 \% \mathrm{Ag}$ ) annealed at $773 \mathrm{~K}$ is shown in Figure 6b. All samples exhibit a p-type to $\mathrm{n}$-type conversion with increasing temperature as shown in Table 1 and Figure 6. It can be seen from
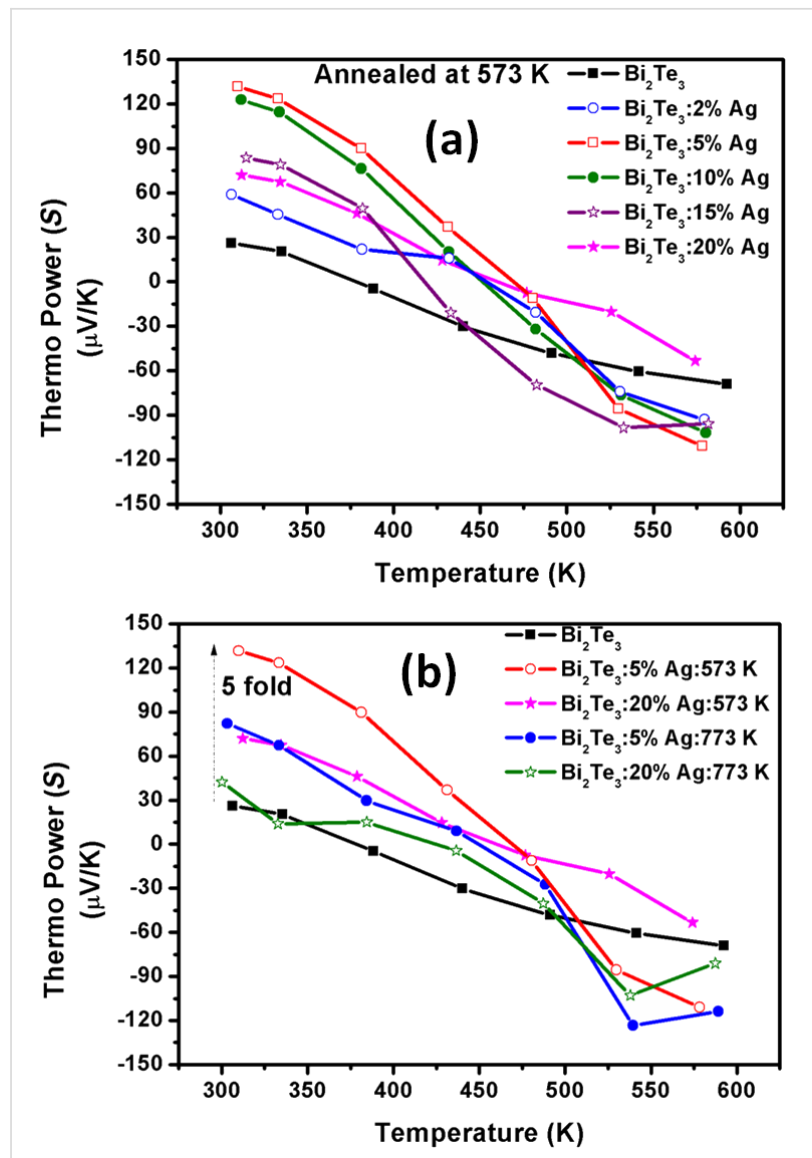

Figure 6: Temperature dependent thermo power measurement $(S)$ of (a) $\mathrm{Bi}_{2} \mathrm{Te}_{3}$ with $(0,2,5,10,15,20 \%) \mathrm{Ag}$ content annealed at $573 \mathrm{~K}$, and (b) comparison of $(0,5,20 \%)$ annealed at $573 \mathrm{~K}$ with $(5,20 \%)$ $773 \mathrm{~K}$ samples in the temperature range $300-600 \mathrm{~K}$.

Table 1: Comparison of electrical conductivity $(\sigma)$, Seebeck coefficient $(S)$ and power factor $\left(S^{2} \sigma\right)$ at 300 and $600 \mathrm{~K}$ of all samples.

\begin{tabular}{|c|c|c|c|c|c|c|c|}
\hline \multirow{2}{*}{$\begin{array}{l}\text { Ag content } \\
\text { annealed at } \\
573 \mathrm{~K}\end{array}$} & \multicolumn{2}{|c|}{$\begin{array}{l}\text { Seebeck coefficient }(S) \\
(\mu \mathrm{V} / \mathrm{K}) \text {, approximate values }\end{array}$} & \multirow{2}{*}{$\begin{array}{l}\text { transition } \\
\text { temp }(\mathrm{K}) \\
\text { (at } 0 \mu \mathrm{V} / \mathrm{K}, \\
\text { p-type to } \\
\text { n-type) }\end{array}$} & \multicolumn{2}{|c|}{$\begin{array}{l}\text { conductivity }(\sigma) \\
(\Omega \cdot \mathrm{cm})^{-1}, \text { approximate values }\end{array}$} & \multicolumn{2}{|c|}{$\begin{array}{l}\text { power factor }\left(S^{2} \sigma\right) \\
\left(\mu \mathrm{W} \cdot \mathrm{m}^{-1} \cdot \mathrm{K}^{-2}\right) \text {, approximate } \\
\text { values }\end{array}$} \\
\hline & $\begin{array}{l}300 \mathrm{~K} \\
\text { (p-type) }\end{array}$ & $\begin{array}{l}600 \mathrm{~K} \\
\text { (n-type) }\end{array}$ & & $300 \mathrm{~K}$ & $600 \mathrm{~K}$ & $300 \mathrm{~K}$ & $600 \mathrm{~K}$ \\
\hline $0 \%$ & 26 & -69 & 378 & 148 & 297 & 10 & 142 \\
\hline $2 \%$ & 59 & -93 & 453 & 75 & 215 & 21 & 186 \\
\hline $5 \%$ & 131 & -111 & 469 & 30 & 135 & 50 & 166 \\
\hline $10 \%$ & 122 & -101 & 451 & 42 & 100 & 63 & 104 \\
\hline $15 \%$ & 83 & -95 & 417 & 28 & 61 & 19 & 56 \\
\hline $20 \%$ & 72 & -53 & 459 & 8 & 34 & 4 & 10 \\
\hline \multicolumn{8}{|l|}{$\begin{array}{l}\text { annealed at } \\
773 \mathrm{~K}\end{array}$} \\
\hline $5 \%$ & 82 & -113 & 450 & 102 & 316 & 69 & 410 \\
\hline $20 \%$ & 42 & -81 & 425 & 92 & 381 & 16 & 251 \\
\hline
\end{tabular}


Table 1, that the transition temperatures vary with different $\mathrm{Ag}$ content and the minimum temperature is ca. $378 \mathrm{~K}$ for $0 \% \mathrm{Ag}$ whereas the maximum transition temperature is $469 \mathrm{~K}$ for $5 \%$ Ag. At room temperature, $S$ has a minimum the lowest value of ca. $26 \mu \mathrm{V} / \mathrm{K}$ for $\mathrm{Ag}$-free $\mathrm{Bi}_{2} \mathrm{Te}_{3}$, which increases to a maximum value at $5 \% \mathrm{Ag}$. The value decreases again with increasing $\mathrm{Ag}$ content after annealing at $573 \mathrm{~K}$. It is interesting to note that all samples show n-type behavior at $600 \mathrm{~K}$. At $600 \mathrm{~K}, S$ increases with increasing Ag content, $S \approx-69 \mu \mathrm{V} / \mathrm{K}(0 \% \mathrm{Ag})$ which increases up to the maximum value of $S \approx-111 \mu \mathrm{V} / \mathrm{K}$ at $5 \% \mathrm{Ag}$. At higher $\mathrm{Ag}$ contents, there is a decrease to $S \approx-101 \mu \mathrm{V} / \mathrm{K}$ for $10 \%, S \approx-95 \mu \mathrm{V} / \mathrm{K}$ for $15 \%$ and $S \approx-53 \mu \mathrm{V} / \mathrm{K}$ for $20 \%$. After annealing at $573 \mathrm{~K}$, the thermopower at room temperature for $5 \% \mathrm{Ag}$ is enhanced by ca. $400 \%$ compared to $0 \% \mathrm{Ag}$, while only a 2.8 -fold increase has been observed for $20 \% \mathrm{Ag}$ content in $\mathrm{Bi}_{2} \mathrm{Te}_{3}$. At $600 \mathrm{~K}$, there is a $60 \%$ enhancement for $5 \% \mathrm{Ag}$ in comparison to $\mathrm{Ag}$-free $\mathrm{Bi}_{2} \mathrm{Te}_{3}$.

For the samples annealed at $773 \mathrm{~K}$, the Seebeck coefficient of $5 \% \mathrm{Ag}$ is three-times that of $0 \% \mathrm{Ag}$ at room temperature. It shows the same enhancement of ca. $60 \%$ as $5 \% \mathrm{Ag}$ annealed at $573 \mathrm{~K}$ in comparison to $0 \% \mathrm{Ag}$ at $600 \mathrm{~K}$. The details are given in Table 1 and Figure $6 \mathrm{~b}$.

There is transition of from p-type to n-type behavior with increasing temperature which may be attributed to bipolar diffusion $[25,26]$ and phase transitions $[27,28]$. In the chalcogenide $\mathrm{AgBiSe}_{2}$, there is an exchange of $\mathrm{Ag}$ and $\mathrm{Bi}$ atoms in the lattice during the phase transition from rhombohedral to cubic that results in the change from p-type to n-type behavior. The exchange of $\mathrm{Ag}$ and $\mathrm{Bi}$ atoms results in a quasi-metallic state that contributes more conduction electrons, and results in a change from p-type to n-type conduction [27]. A similar work has shown a change in the Seebeck coefficient of AgCuS along with a change in conduction during the phase transition from orthorhombic to hexagonal [28]. In our study, bipolar diffusion with increasing temperature may be responsible for the $\mathrm{p}-\mathrm{n}$ type transition. At room temperature, holes are the majority carriers (p-type). When a certain temperature is reached, the $S$ becomes zero, because both carrier concentrations become equal $\left(\mathrm{n}+, \mathrm{n}^{-}\right)$. On further increasing the temperature electrons become the majority carriers (n-type) [25]. Another reason for a p-n-type transition is $\mathrm{Ge}$ substituting $\mathrm{Bi} / \mathrm{Te}$ in $\mathrm{Bi}_{2} \mathrm{Te}_{3}$ [26]. Our XRD does not show any phase transition. Hence, we suppose that only bipolar diffusion is the cause for the conduction transition. In order to gain further knowledge about phase transitions and carrier types, further studies such as synchrotron powder X-ray diffraction, heat capacity, Raman spectroscopy, Hall effect and or positron annihilation spectroscopy measurements would be required, which can be the part of a future study.
The enhancement of the Seebeck coefficient can be attributed to carrier filtering. Band bending at the metal-semiconductor interfaces leads to a strong scattering of low-energy electrons whereas high-energy electrons remain unaffected [20,21]. The energy-dependent scattering of electrons is caused by the existence of an electrostatic potential at the interface. The Seebeck coefficient depends on the energy derivative of the relaxation time at the Fermi energy. Thus the electron-energy filtering, in which high-energy electrons remain unaffected, strongly enhances Seebeck coefficient. [20,21,29]. In our samples, one can clearly observe the increased Seebeck coefficient for $5 \%$ $\mathrm{Ag}$ at the lower annealing temperature, which decreases again for higher Ag content because of the smaller nanoparticles $(<30 \mathrm{~nm})$ in the matrix. For the higher annealing temperatures, there is the same trend, but the values of $S$ are smaller, which may be attributed to the formation of one type of mainly hexagonal nanoparticles with a wide size distribution as discussed in TEM results.

\section{Power factor $\left(S^{2} \sigma\right)$}

Figure 7a,b shows the power factor $\left(S^{2} \sigma\right)$ in the temperature range $300-600 \mathrm{~K}$ (also given in Table 1). It is evident that for
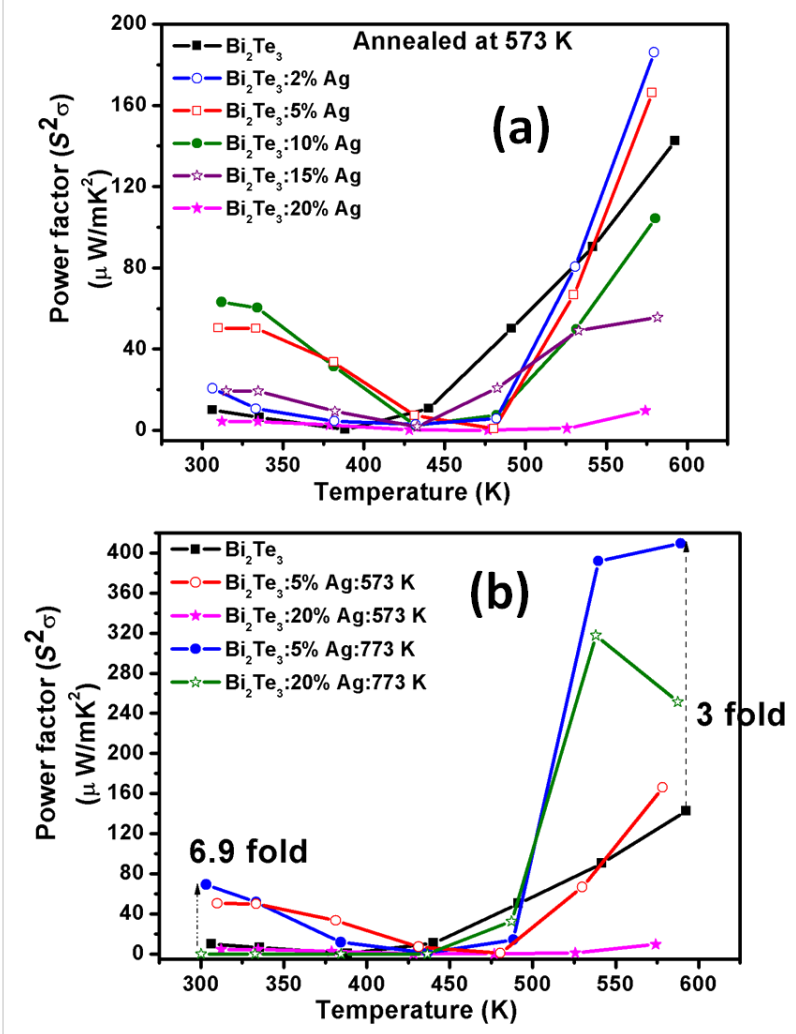

Figure 7: Power factor $\left(S^{2} \sigma\right)$ as a function of the temperature (a) $\mathrm{Bi}_{2} \mathrm{Te}_{3}$ with $(0,2,5,10,15,20 \%) \mathrm{Ag}$ content annealed at $573 \mathrm{~K}$, and (b) comparison of $(0,5,20 \%) \mathrm{Ag}$ content annealed at 573 and $773 \mathrm{~K}$. 
$\mathrm{Bi}_{2} \mathrm{Te}_{3}$ annealed at $573 \mathrm{~K}$, the power factor increases with increasing $\mathrm{Ag}$ content up to $10 \% \mathrm{Ag}$, and decreases again up to $20 \% \mathrm{Ag}$ at room temperature. At $600 \mathrm{~K}$, the power factor first increases for $2 \% \mathrm{Ag}$ then it decreased up to $20 \% \mathrm{Ag}$. For the samples annealed at $773 \mathrm{~K}$, the power factor increases for $5 \% \mathrm{Ag}$ at room temperature and the highest value of ca. $410 \mu \mathrm{W} \cdot \mathrm{m}^{-1} \cdot \mathrm{K}^{-2}$ is observed at $600 \mathrm{~K}$. The power-factor enhancement compared with $0 \% \mathrm{Ag}$ is ca 6.9 -times at $300 \mathrm{~K}$ and ca. three-times at $600 \mathrm{~K}$ for $5 \% \mathrm{Ag}$, annealed at $773 \mathrm{~K}$. For samples annealed at $573 \mathrm{~K}$, the power-factor enhancement is ca. 6.3-times for $10 \% \mathrm{Ag}$ at $300 \mathrm{~K}$ and 1.3 -times for $2 \% \mathrm{Ag}$ at $600 \mathrm{~K}$.

The nanoparticles in the semiconductor matrix also lead to a reduction of thermal conductivity through phonon scattering at the interfaces, which in turn increases the figure of merit. The present work shows that during the incorporation of $\mathrm{Ag}$ in a $\mathrm{Bi}_{2} \mathrm{Te}_{3}$ matrix the distribution of nanoparticles size and shape can be tuned through the annealing temperature, which consequently affects the thermoelectric properties as shown in Figure 8. A five-fold enhancement in thermopower and a 6.9-fold enhancement in power factor for 5\% Ag annealed at $573 \mathrm{~K}$ and $773 \mathrm{~K}$, respectively, have been achieved in comparison to $\mathrm{Ag}$-free $\mathrm{Bi}_{2} \mathrm{Te}_{3}$.

Our motivation was to focus on low cost and a quick and uncomplicated large-scale production of an efficient nanostruc- tured TE material. In this work, $\mathrm{Bi}_{2} \mathrm{Te}_{3}$ bulk powder and micrometer-sized Ag particles were commercially purchased to avoid variations of intrinsic properties during the synthesis of both $\mathrm{Ag}$ and $\mathrm{Bi}_{2} \mathrm{Te}_{3}$. In the present work, the bulk $\mathrm{Bi}_{2} \mathrm{Te}_{3}$ has a Seebeck coefficient of ca. $26 \mu \mathrm{V} / \mathrm{K}$, which is very low in comparison to synthesized $\mathrm{Bi}_{2} \mathrm{Te}_{3}$ reported in previous reports. However, our main focus is not to compare our results with previous reports, but to study in detail the effect of different Ag contents in $\mathrm{Bi}_{2} \mathrm{Te}_{3}$ and the effect of the annealing temperature on shape and size of the nanoparticles. It can be speculated from the above results that ca. $400 \%$ enhancement of $S$ and ca. $600 \%$ enhancement of $S^{2} \sigma$ due to $\mathrm{Ag}$ nanoparticles in $\mathrm{Bi}_{2} \mathrm{Te}_{3}$ will also be possible when higher initial values of Seebeck coefficient and power factor for $\mathrm{Ag}$-free $\mathrm{Bi}_{2} \mathrm{Te}_{3}$ are achieved.

\section{Conclusion}

In summary, different sizes and shapes of $\mathrm{Ag}$ nanoparticles in different fractions (0-20 wt \%) were added to a $\mathrm{Bi}_{2} \mathrm{Te}_{3}$ matrix for a systematic investigation of temperature-dependent thermoelectric properties. Transmission electron microscopy revealed circular, hexagonal, tube-like structures for samples annealed at $573 \mathrm{~K}$, whereas only hexagonal structures were visible for samples annealed at $773 \mathrm{~K}$. The size distribution is also affected by the annealing temperature as smaller size particles $(<30 \mathrm{~nm})$ has been found after annealing at $573 \mathrm{~K}$, while together with smaller particles $(<30 \mathrm{~nm})$, there are also bigger particles $(<80 \mathrm{~nm})$ for samples annealed at $773 \mathrm{~K}$. For the same

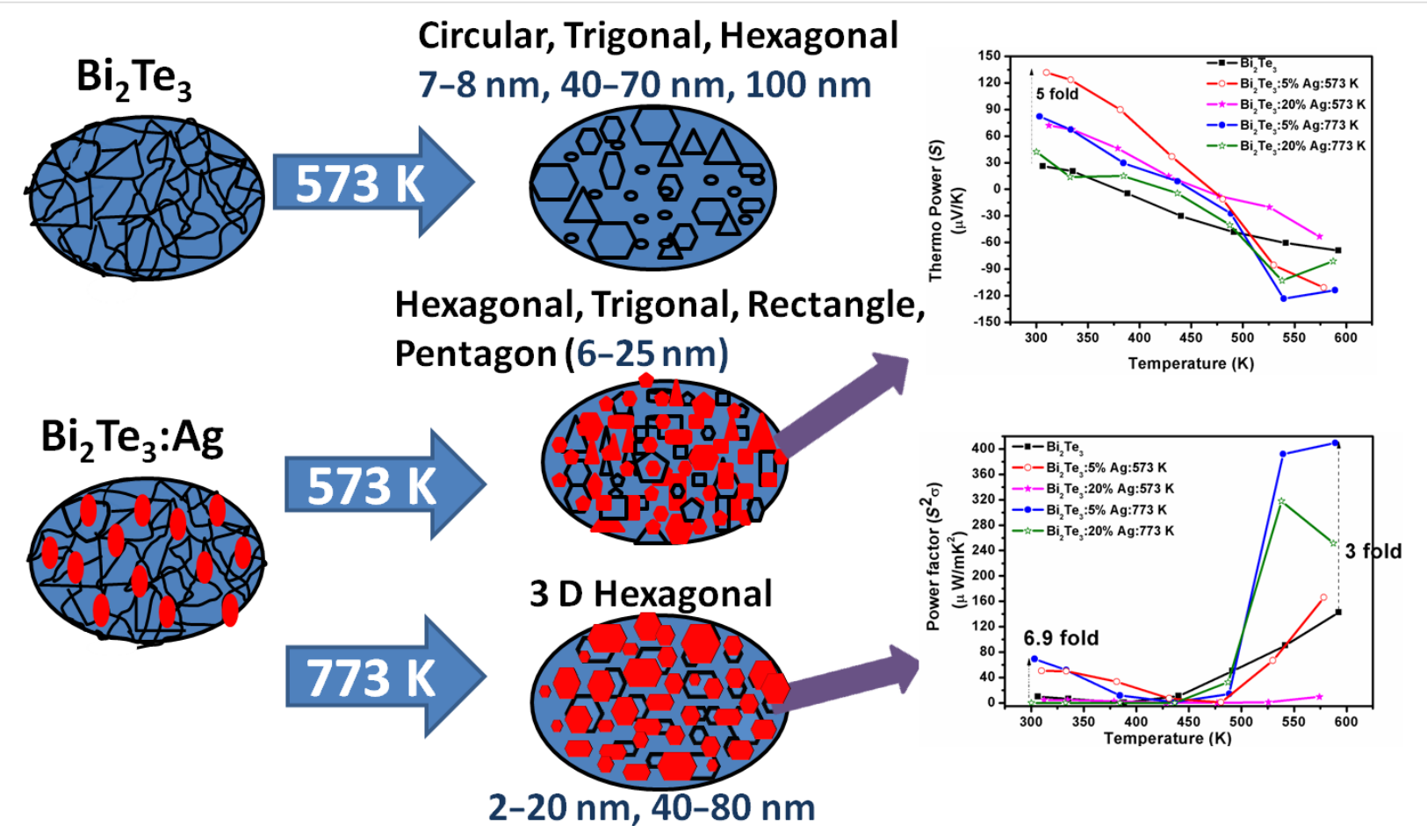

Figure 8: Schematic of effect of $\mathrm{Ag}$ nanoparticles in $\mathrm{Bi}_{2} \mathrm{Te}_{3}$ leads to the enhancement in thermoelectric properties. 
annealing temperature, a change in Ag content has a a negligible effect on size and shape, whereas a change in annealing temperature leads to change in shape as well as size even for the same content of Ag. For the same content of Ag nanoparticles in $\mathrm{Bi}_{2} \mathrm{Te}_{3}$, the Seebeck coefficient at room temperature increased five-fold after annealing at $573 \mathrm{~K}$, whereas the power factor was enhanced 6.9-fold after annealing at $773 \mathrm{~K}$ in comparison to $\mathrm{Ag}$-free $\mathrm{Bi}_{2} \mathrm{Te}_{3}$. This enhancement can be understood on the basis of carrier-filtering. In future, these findings can be helpful to achieve a reduction in thermal conductivity, which in turn will lead to a high figure of merit required for day-to-day thermoelectric applications.

\section{Acknowledgements}

One of the authors Srashti Gupta is thankful to UGC to sponsor the research under the UGC Dr. D. S. Kothari Post Doctoral Fellowship (BSR/PH/14-15/0066) Scheme. DKA acknowledges Department of Science and Technology for XRD under IRHPA project and SEM under Nano Mission project.

\section{ORCID ${ }^{\circledR}$ iDs}

Kandasami Asokan - https://orcid.org/0000-0002-0613-219X

\section{References}

1. Hicks, L. D.; Dresselhaus, M. S. Phys. Rev. B 1993, 47, 12727-12731. doi:10.1103/physrevb.47.12727

2. Dresselhaus, M. S.; Chen, G.; Tang, M. Y.; Yang, R. G.; Lee, H.; Wang, D. Z.; Ren, Z. F.; Fleurial, J. P.; Gogna, P. Adv. Mater. (Weinheim, Ger.) 2007, 19, 1043-1053. doi:10.1002/adma.200600527

3. Gupta, S.; Agarwal, D. C.; Tripathi, S. K.; Neeleshwar, S.; Panigrahi, B. K.; Jacquot, A.; Lenoir, B.; Avasthi, D. K. Radiat. Phys. Chem. 2013, 86, 6-9. doi:10.1016/j.radphyschem.2013.01.009

4. Bala, M.; Gupta, S.; Srivastava, S. K.; Amrithapandian, S.; Tripathi, T. S.; Tripathi, S. K.; Dong, C.-L.; Chen, C.-L.; Avasthi, D. K.; Asokan, K. Phys. Chem. Chem. Phys. 2017, 19, 24886-24895. doi:10.1039/c7cp03527f

5. Bala, M.; Gupta, S.; Tripathi, T. S.; Varma, S.; Tripathi, S. K.; Asokan, K.; Avasthi, D. K. RSC Adv. 2015, 5, 25887-25895. doi:10.1039/c5ra01000d

6. Gupta, S.; Agarwal, D. C.; Khan, S. A.; Neeleshwar, S.; Ojha, S.; Srivastava, S.; Tripathi, A.; Amirthapandian, S.; Panigrahi, B. K.; Avasthi, D. K. Mater. Sci. Eng., B 2014, 184, 58-66. doi:10.1016/j.mseb.2014.01.002

7. Gupta, S.; Agarwal, D. C.; Prakash, J.; Khan, S. A.; Tripathi, S. K.; Tripathi, A.; Neeleshwar, S.; Srivastava, S. K.; Panigrahi, B. K.; Chandra, R.; Avasthi, D. K. Nucl. Instrum. Methods Phys. Res., Sect. B 2012, 289, 22-27. doi:10.1016/j.nimb.2012.07.036

8. Gupta, S.; Neeleshwar, S.; Kumar, V.; Chen, Y. Y. Adv. Mater. Lett. 2012, 3, 50-54.

9. Venkatasubramanian, R.; Siivola, E.; Colpitts, T.; O'Quinn, B. Nature 2001, 413, 597-602. doi:10.1038/35098012

10. Row, D. M. CRC Handbook of Thermoelectrics, 1st ed.; CRC Press: Boca Raton, 1995. doi:10.1201/9781420049718
11. Faleev, S. V.; Léonard, F. Phys. Rev. B 2008, 77, 214304. doi:10.1103/physrevb.77.214304

12. Zebarjadi, M.; Esfarjani, K.; Shakouri, A.; Bahk, J.; Bian, Z.; Zeng, G.; Bowers, J.; Lu, H.; Zide, J.; Gossard, A. Appl. Phys. Lett. 2009, 94, 202105. doi:10.1063/1.3132057

13. Ma, Y.; Heijl, R.; Palmqvist, A. E. C. J. Mater. Sci. 2013, 48, 2767-2778. doi:10.1007/s10853-012-6976-z

14. Zhang, Y.; Stucky, G. D. Chem. Mater. 2014, 26, 837-848. doi:10.1021/cm402150j

15. Sumithra, S.; Takas, N. J.; Misra, D. K.; Nolting, W. M.; Poudeu, P. F. P.; Stokes, K. L. Adv. Energy Mater. 2011, 1, 1141-1147. doi:10.1002/aenm.201100338

16. Zhang, Q.; Xu, L.; Zhou, Z.; Wang, L.; Jiang, W.; Chen, L. J. Appl. Phys. 2017, 121, 055104. doi:10.1063/1.4975467

17. Kim, K. T.; Eom, Y. S.; Son, I. J. Nanomater. 2015, No. 202415. doi:10.1155/2015/202415

18. Han, M.-K.; Yu, B.-G.; Jin, Y.; Kim, S.-J. Inorg. Chem. Front. 2017, 4, 881-888. doi:10.1039/c6qi00544f

19. Zhang, Q.; Ai, X.; Wang, W.; Wang, L.; Jiang, W. Acta Mater. 2014, 73, 37-47. doi:10.1016/j.actamat.2014.03.070

20. Zhang, Q.; Ai, X.; Wang, L.; Chang, Y.; Luo, W.; Jiang, W.; Chen, L. Adv. Funct. Mater. 2015, 25, 966-976. doi:10.1002/adfm.201402663

21. Kim, Y.-J.; Choi, S. H.; King, G. C.; Park, Y.; Lee, K. Method of creating micro-scale silver telluride grains covered with bismuth nanoparticles. U.S. Patent US 8,691,612 B2, April 8, 2014.

22. Gatan Microscopy Suite ${ }^{\circledR}$ (GMS) is the industry standard software for (scanning) transmission electron microscope experimental control and analysis, http://www.gatan.com/products/tem-analysis/gatan-microscopy-suite-s oftware

23. Image $J$ is an open source image processing program designed for scientific multidimensional images, https://imagej.net/Welcome

24. Das, V. D.; Bhat, K. S. J. Phys. D: Appl. Phys. 1989, 22, 162-168. doi:10.1088/0022-3727/22/1/023

25. Xu, G.-Y.; Niu, S.-T.; Wu, X.-F. J. Appl. Phys. 2012, 112, 073708. doi:10.1063/1.4754840

26. Wu, H.-j.; Chen, B.-Y.; Cheng, H.-Y. Acta Mater. 2017, 122, 120-129. doi:10.1016/j.actamat.2016.09.043

27. Xiao, C.; Qin, X.; Zhang, J.; An, R.; Xu, J.; Li, K.; Cao, B.; Yang, J.; Ye, B.; Xie, Y. J. Am. Chem. Soc. 2012, 134, 18460-18466. doi:10.1021/ja308936b

28. Guin, S. N.; Pan, J.; Bhowmik, A.; Sanyal, D.; Waghmare, U. V.; Biswas, K. J. Am. Chem. Soc. 2014, 136, 12712-12720. doi:10.1021/ja5059185

29. Kim, H. J.; King, G.; Park, Y.; Lee, K.; Choi, S. Thermoelectric Performance Enhancement by Surrounding Crystalline Semiconductors with Metallic Nanoparticles. 9th Annual International Energy Conversion Engineering Conference, San Diego, July 31-Aug 3, 2011; report AIAA 2011-5982. doi:10.2514/6.2011-5982 


\section{License and Terms}

This is an Open Access article under the terms of the Creative Commons Attribution License (http://creativecommons.org/licenses/by/4.0). Please note that the reuse, redistribution and reproduction in particular requires that the authors and source are credited.

The license is subject to the Beilstein Journal of Nanotechnology terms and conditions:

(https://www.beilstein-journals.org/bjnano)

The definitive version of this article is the electronic one which can be found at:

doi:10.3762/bjnano.10.63 